\section{Postmortem Organ Procurement for Transplantation}

THE 1-YEAR SURVIVAL RATE of recipients of heart and liver transplants now exceeds that for recipients of postmortem donor kidney transplants according to recent reports (1-5). Very promising early results with pancreas and heart-lung transplants have also been reported (6, 7). These accomplishments are due largely to advances in the clinical treatment of allograft rejection. Kidney transplantation programs are well established; extrarenal transplantation programs for other organs will multiply rapidly in the months ahead to meet burgeoning needs. Liver transplantation was recently inaugurated at Massachusetts General Hospital, and cardiac transplantation will soon be initiated at Peter Bent Brigham Hospital. In the next few years, the number of patients in the United States who could benefit from transplants of organs other than kidneys is likely to exceed the nearly 6000 patients now waiting for cadaveric renal transplantation.

The shortage of suitable postmortem organs is clearly impeding wider use of solid organ transplantation. During a recent 2-year period at our center, for instance, 71 patients waiting for a liver transplant died before a donor organ became available. Congressional hearings were held recently to assess the reasons for the shortfall in organs. The Investigations and Oversight Subcommittee of the House Science and Technology Committee (8) heard expert witnesses report that in 1982 only 2200 of the estimated 20000 potential donors dying in American hospitals actually yielded organs for transplantation. The Surgeon General convened a workshop in June to seek remedies for this shortage.

Specialists at the nation's 110 organ procurement programs state that at least three out of four families offered an opportunity to donate organs of family members suffering from brain death are willing to do so (8). Preoccupied with their own loss, however, these families seldom think to volunteer such donations unless informed of that option.

Regional donor programs provide 24-hour assistance in donor evaluation, discussions with surviving family members, and maintenance of donor organ function after determination of brain death. These programs are also available to remove and preserve donor organs for transplantation. Each regional program has up-to-date information on the need for extrarenal donors at centers performing heart, heart-lung, liver, and pancreas transplants through a nationwide organ-sharing system. Cooperation between surgical teams from geographically distant centers in procuring multiple solid organs is now 'a routine experience (9). At our center $70 \%$ of over 200 extrarenal organs transplanted have been recovered with the help of procurement teams 100 to 1500 miles distant from Pittsburgh.

The participation of physicians attending victims of total, irreparable destruction of brain function is critical to facilitate postmortem donation and recovery of organs. They should consider contacting their local organ-procurement team for information and assistance. Physicians unsure of how to reach the nearest procurement program can quickly secure this information by calling 800-24DONOR (800-243-6667), à nationwide transplant hotline operated by the North American Transplant Coordinators Organization (NATCO). Staffed by procurement personnel at the University of Pittsburgh, the NATCO
24-DONOR center can also provide information about the need for extrarenal organs at major centers in the United States and Canada. (DAVID H. VAN THIEL M.D.; Thomas E. STARZL, M.D.; and DONALD W. DeN. NY, M.S.W.; University of Pittsburgh, Pittsburgh, Penn. sylvania)

\section{REFERENCES}

1. REITZ BA. Stinson EB. Cardiac Iransplantation-1982. JAMA 1982;248:1225-7.

2. Griffith BP. Hardesty RL, Deeb GM, Stázzl TE, Bahnson ht Cardiac transplantation with cyclosporin $A$ and prednisone. Ann Sur
1982;196:324.9.

3. Starzl TE. Iwatsuki S, Van Thifl DH, et al. Evaluation of the transplantation. Hepatology. 1982;2:614-36.

4. VAN ThIEL DH, SCHADE RR, STARZL TE, et al. Liver transplantation in adults. Hepatology. 1982;2:637-40.

3. GUTtMAN RD. Renal transplantation. N Eng/J Med. 1979;301:103en

6. Reitz BA, WAllwork JL, HUNT SA, PENNOCK JL. Hean-lung tra plantation: successful therapy for patients with pulmonory vasculas ease. N Engl J Med. 1982;306:557-64.

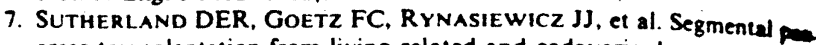
creas transplantation from living related and cadaveric donors: a ctions experience. Surgery. 1981;90:159-69.

8. Transcript of Hearings on Procurement and Distribution of Humm a gans for Transplantation Before the Subcomittee on Investigations an Oversight, Committee on Science and Technology, U.S. House of Rem sentatives, 13, 14, 27 April 1983

9. Shaw BW JR, HaKala T, Rosentrhal JT, Iwatsuki S, Broznica STARZL TE. Combination donor hepatectomy and nephrectomy and ly functional results of allografts. Surg Gynecol Obstet. 1982;155.321.8 01983 American College of Physicians

\section{Reprint of Annotated Bibliographies and Library for} Internists IV

A COLLECTIVE reprint containing the 14 annotated liographies compiled for the Medical Knowledge Assessment Program (MKSAP) VI, three other ansom ed bibliographies on topics also of interest to interning and The Library for Internists $I V$ is now available.

In compiling the MKSAP bibliographies, the Mrent committees reviewed MEDLINE printouts of journ ticles published since 1978 and drew on sources 1 be available in medical libraries in the United Stant Canada. Most of the bibliographies in each suberpic area contain about 100 citations to original and papers and similar sources that represent importint velopments in the concept and practice of internal cine. The other annotated bibliographies included reprint were published in the journal in 1982 and are not part of the MKSAP program: Th medical illness and pregnancy, education for: medicine, and clinical research methods. The $L$. Internists $I V$ lists 150 books and 50 journals reco ed by the American College of Physicians as a a small personal or hospital library; the book annotated. Subjects covered in The Library inch eral internal medicine, the 14 areas coverds MKSAP program, and 23 other disciplines medical science.

Détails for ordering the collected reprint page 424 of this issue. We believe these annotated
raphies and lists will aid those seeking to keep developments in internal medicine and to build s of current literature.-The Editor. 